\title{
Research on The Financial Risk Evaluation of the Innovative Enterprise
}

\author{
Li Ai-li ,Sun Xiao-yi \\ Shandong Pingdu audit bureau, Qingdao Guoxin City net construction Ltd. \\ Shandong Qingdao,China, 266700 \\ Email:sixu1016@163.com
}

\begin{abstract}
The financial situation and financial demand have many uncertainty factors. Therefore, innovative enterprises need to clear their own financial risk profile and scientifically evaluate the risk status of affairs. From two aspects of financial indicators and non-financial indicators of risk,It set up a financial risk evaluation index system of innovative enterprises including investment risk, the risk of the turnover fund and management, the income risk , the internal environment and external environment, Human capital and $R \& D$ cost. It comprehensively analyze the effect in financial risk. Using Fuzzy comprehensive evaluation method, it made an empirical evaluation of the financial risk of innovative enterprises.
\end{abstract}

Keywords-component; The Innovative Enterprise;The Financial Risk;Evaluation;Fuzzy

\section{INTRODUCTION}

Under the background of global economic new adjusting, it is important of the growth of Innovative enterprise for national or local economy. Currently. But, there are many problems for the development of the inovative enterprise. First of all, enterprise is short of the health and sustaining growth mechanism. Secondly, society is short of the normative and excellent supporting circumstance. The finance is the foundation of the existence and development of innovative enterprises. Innovative enterprises have a greater risk of the financial than the general traditional enterprises during their development. And the financial situation and financial demand have many uncertainty factors. Therefore, innovative enterprises need to clear their own financial risk profile and scientifically evaluate the risk status of affairs.

II. THE CONSTRUCTION OF FINANCIAL RISK EVALUATION SYSTEM OF INNOVATIVE ENTERPRISES BASING ON THE FUZZY COMPREHENSIVE EVALUATION METHOD

\section{A. The establishment of the index system}

From two aspects of financial indicators and nonfinancial indicators of risk, the financial risk evaluation index system could be set up.

First of all, the financial index of financial risk evaluation of innovative enterprises Include the following aspects:

(1) Investment risk. Innovative companies would invest huge capital in the early stage,which makes the assets and liabilities rate fixed assets ratio would be usually higher,liquidity ratio would be low. So the short-term investment risk would be great.
(2) The risk of fund turnover and management. The turnover ratio of receivable, turnover ratio of inventory , capital structure and the interest risk are important for the innovative enterprise. Because of the development and production of the innovative enterprise are high-tech products which generally does not require large amounts of raw materials

(3) Income risk. The ultimate goal of the innovative enterprise is to increase the business profitability. The Income evaluation index could increase the enterprise wealth.

The financial index data come from financial statements which may not be able to give a fair and true information to the company financial situation. It is not conducive to guide management behavior. So we should consider the nonfinancial factors to reasonable evaluate the financial risk of the innovative enterprise. Non-financial indicators include the following:

(1) External environment

External environment includes economic environment, Industrial development environment, legal and policy environment, sociocultural environment, the development level of science and technology, the level of financial services and so on.

(2) Internal environment

Internal environment includes enterprise financial strategy, corporate governance structure, properties and structure of stock right, the level of enterprise financial flexibility, corporate culture etc.

(3) The Input level of Human capital and R\&D cost

The ratio of technology and $\mathrm{R} \& \mathrm{D}$ personnel, the quality of financial management professionals and $K \& D$ investment represent the enterprise's R \& D and intangible assets to a certain degree. Which effect the technological innovation capability and the future profitability of innovative enterprise.

\section{B. Financial risk assessment method selection}

The financial situation and the financial risk of enterprises are fuzzy concepts. The fuzzy comprehensive evaluation method is a method of evaluation for the practical evaluation using the concept of fuzzy mathematics.

It constructed the hierarchy fuzzy subset to quantizate fuzzy index basing on fuzzy Mathematics. Then made a comprehensive evaluation to each index using the principle of fuzzy transform.

Fuzzy comprehensive evaluation model : 
$A \circ R=\left(a_{1}, a_{2}, \cdots, a_{p}\right)\left[\begin{array}{lll}r_{11} & r_{12} \cdots r_{1 m} \\ r_{21} & r_{22} \cdots r_{2 m} \\ \vdots & \vdots & \\ r_{p 1} & r_{p 2} \cdots r_{p m}\end{array}\right]=\left(b_{1}, b_{2}, \cdots, b_{m}\right) \approx B$

$A \circ R$ is the Synthesis of $A$ and $R, \circ$ is the Synthesis operator. ${ }^{b}{ }_{j}$ is obtained by $A$ and The J column of $R$. Which means the degree of belonging to $v_{j}$.

III. THE EMPIRICAL RESEARCH ON FINANCIAL RISK ASSESSMENT OF THE INNOVATIVE ENTERPRISE BASED ON THE FUZZY COMPREHENSIVE EVALUATION METHOD

In this paper, taking MESNAC CO.LTD as a case,we analyzed the financial risk of the innovative enterprise using Fuzzy comprehensive evaluation method. The procedure is as follows:

A. Giving the factor domain of financial risk evaluation of MESNAC:

$U_{i}=\left[u_{i 1}, u_{i 2}, u_{i 3}\right] \quad i=1,2$

among them:

$U_{1}$ - financial risk index

$U_{2} \_$non-financial risk index

$u_{11 \_ \text {investment risk }}$

$u_{12}$ — the risk of fund turnover and management

$u_{13} \ldots$ _ income risk

$u_{21}$ — the external environment of enterprises

$u_{22}$ _ the internal environment of enterprises

$u_{23}$ _ Input level of human capital and R\&D cost

B. Giving the remark grade domain of financial risk evaluation of MESNAC:

$V=\left[v_{1}, v_{2}, v_{3}\right]$

among them:

$v_{1}$ Less risk

$v_{2} \longrightarrow$ Medium risk

$v_{3} \_$Greater risk

C. Establishing fuzzy relationship matrix $R$ and doing the single factor evaluation:

$$
R=\left(R_{1}, R_{2}\right)
$$

among them:
$R_{1}$ _ fuzzy relationship matrix of financial indicator evaluation

$R_{2}$ - - fuzzy relationship matrix of non-financial indicator evaluation

$$
R_{i}=\left[\begin{array}{l}
R_{i} \mid u_{i 1} \\
R_{i} \mid u_{i 2} \\
R_{i} \mid u_{i 3}
\end{array}\right]=\left[\begin{array}{ccc}
r_{11} & r_{12} & r_{13} \\
r_{21} & r_{22} & r_{23} \\
r_{31} & r_{32} & r_{33}
\end{array}\right]_{3 \times 3}
$$$$
\text { ( } i=1,2)
$$

Expert survey:

$$
R_{1}=\left[\begin{array}{l}
R_{1} \mid u_{11} \\
R_{1} \mid u_{12} \\
R_{1} \mid u_{13}
\end{array}\right]=\left[\begin{array}{lll}
0.429 & 0.357 & 0.214 \\
0.357 & 0.321 & 0.321 \\
0.321 & 0.286 & 0.393
\end{array}\right]_{3 \times 3}
$$

$$
R_{2}=\left[\begin{array}{l}
R_{2} \mid u_{21} \\
R_{2} \mid u_{22} \\
R_{2} \mid u_{23}
\end{array}\right]=\left[\begin{array}{lll}
0.286 & 0.250 & 0.464 \\
0.321 & 0.393 & 0.286 \\
0.424 & 0.357 & 0.214
\end{array}\right]_{3 \times 3}
$$

Giving the fuzzy weight vector of financial risk factors of MESNAC:

$A=\left(A_{1}, A_{2}\right)$,among them $A_{1}, A_{2}$ are fuzzy weight vectors of financial risk index and non-financial risk index in the financial risk evaluation index system of MESNAC. Through consulting experts, the fuzzy weight vectors could be given:

$$
\begin{aligned}
& A_{1}=(0.316,0.263,0.421) \\
& A_{2}=(0.263,0.395,0.342)
\end{aligned}
$$

E. Giving the fuzzy comprehensive evaluation vector of financial risk of MESNAC:

$$
B=\left(B_{1}, B_{2}\right)
$$

among them:

$B_{1}$ _ the fuzzy comprehensive evaluation vector of financial risk index

$B_{2}$ _ — the fuzzy comprehensive evaluation vector of non-financial risk index

For

$A \circ R=\left(a_{1}, a_{2}, \cdots, a_{p}\right)\left[\begin{array}{ccc}r_{11} & r_{12} \cdots & r_{1 m} \\ r_{21} & r_{22} \cdots & r_{2 m} \\ \vdots & \vdots & \vdots \\ r_{p 1}, & r_{p 2} \cdots & r_{p m}\end{array}\right]=\left(b_{1}, b_{2}, \cdots, b_{m}\right) \approx B$ 


$$
\begin{aligned}
& \text { So } \\
& \begin{array}{c}
A \circ R_{1} \\
=(0.316,0.263,0.421)
\end{array}\left[\begin{array}{lll}
0.429 & 0.357 & 0.214 \\
0.357 & 0.321 & 0.321 \\
0.321 & 0.286 & 0.393
\end{array}\right] \\
& =(0.321,0.316,0.393) \approx B_{1} \\
& A \circ R_{2}=(0.263,0.395,0.342)\left[\begin{array}{lll}
0.286 & 0.250 & 0.464 \\
0.321 & 0.393 & 0.286 \\
0.424 & 0.357 & 0.214
\end{array}\right] \\
& =(0.342,0.393,0.286) \approx B_{2}
\end{aligned}
$$

F. Analyzing the fuzzy comprehensive evaluation vectors of the first grade index

According to the principle of weighted average, the fuzzy comprehensive evaluation vectors of the first grade index could be given. We can sort the results of comprehensive evaluation.

For:

$$
A=\frac{\sum_{j=1}^{m} b_{j}^{k} \bullet j}{\sum_{j=1}^{m} b_{j}^{k}}, k_{=2} A=\left(A_{1}, A_{2}\right)
$$

among them:

$A_{1}$ _- weighted comprehensive evaluation results of financial risk index

$A_{2}$ _- weighted comprehensive evaluation results of non-financial risk index

So:

$$
A_{1=} \frac{1 \times 0.321^{2}+2 \times 0.316^{2}+3 \times 0.393^{2}}{0.321^{2}+0.316^{2}+0.393^{2}}=2.14
$$

$$
A_{2}=\frac{1 \times 0.342^{2}+2 \times 0.393^{2}+3 \times 0.286^{2}}{0.342^{2}+0.393^{2}+0.286^{2}}=1.9
$$

$A_{2}<A_{1}$, according to the result of weighted comprehensive evaluation of MESNA's financial risk,we could find that the risk of the financial risk was bigger than the non-financial risk of MESNAC. In order to reduce the financial risk of the innovative enterprises, it is important to speeding up the accounts receivable turnover rate and stock turnover rate, optimizating capital structure and reducing the interest rate risk

\section{CONCLUSION}

Innovative enterprises have a greater risk than the general traditional enterprises and the financial situation and financial demand have many uncertainty.. So, it is necessary to clear their own financial risk profile to make Long-term interests. From two aspects of financial indicators and nonfinancial indicators of risk, we could consider the qualitative and quantitative factors in the financial risk using fuzzy comprehensive evaluation method. Which is conducive to take targeted measures to reduce the financial risk during the development of innovative enterprises.

\section{REFERENCES}

[1] XU Jie, ZHAO Fang .Fuzzy comprehensive evaluation of enterprise based on multi-levels combined weights informinationization[J]. Journal of Hebei University. 2012(3): 320-325

[2] Shen Youdi, Shen Wang .Effectiveness of Financial Risk Evaluation Indicator for Small and Medium-sized Enterprises in China ' s GEM. [J]. Technology Economics.2012(7): 66-72

[3] Xiang Gang, Chen Zhicao, Li Ning .Major Risk Analysis and Response of Innovative Enterprise Strategic Transformation[J]. Forum on Science and Technology in China. 2012(3) 63-67,103

[4] Thom berry . Dvpgressman Mac,Fostering Culture of Innovation. Proceedings of the United State Naval Institute,2003 : 44-48

[5] Suresh de Mel\&David McKenzie. Innovative Finn or Innovative Owners.Determinants of Innovation in Micro Small,and Medium Enterprise;Discussion Paper No. 3962. 2009 : 2-5 